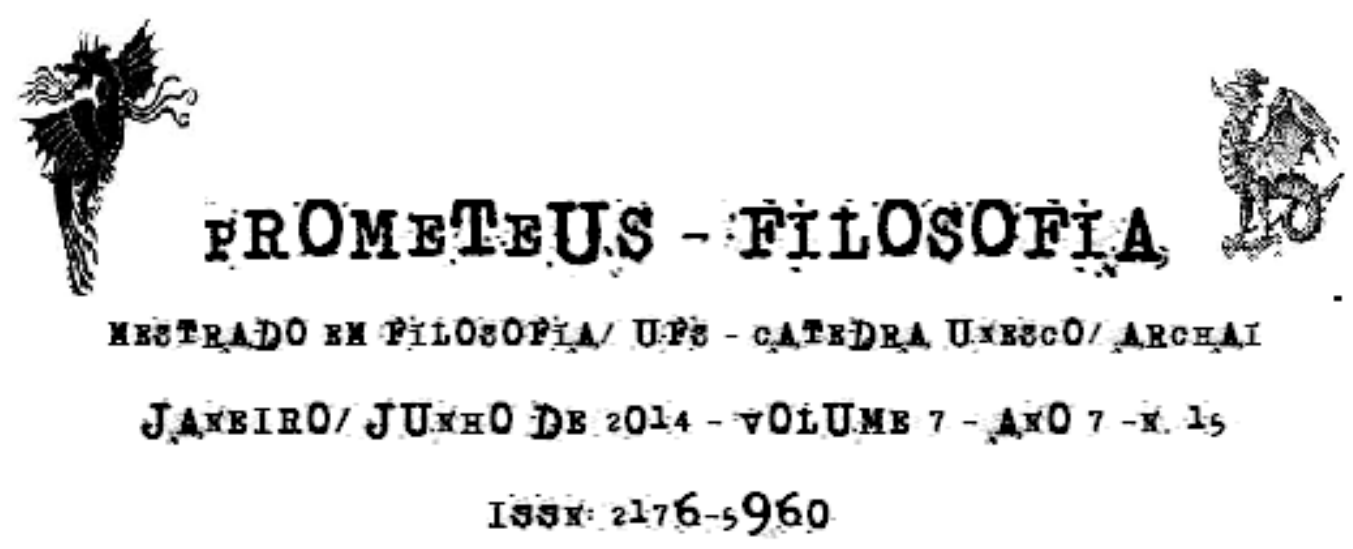

\title{
CARTA DE ÂNGELO POLIZIANO A LORENZO DE MEDICI A RESPEITO DO ENCHEIRIDION DO ESTOICO EPICTETO TRADUZIDO POR POLIZIANO DO GREGO
}

\author{
Tradução de Rineu Quinalia \\ Doutorando em Filosofia pela UFSCar \\ Apresentação de A. Dinucci
}

\begin{abstract}
RESUMO: Niccolò Perotto foi o primeiro a verter o Encheirídion de Epicteto para o latim em 1450. Após Perotto, Ângelo Poliziano realizou uma tradução que, publicada em 1497, tornar-seia extremamente influente ao longo dos séculos seguintes. Poliziano era um protegido dos Médicis, tendo acesso à famosa biblioteca de Lourenço de Médici, a quem dedicou sua tradução.
\end{abstract}

PALAVRAS-CHAVE: Poliziano. Epicteto. Renascença. Estoicismo.

ABSTRACT: Niccolò Perotto was the first to translate the Epictetus Encheiridion into Latin in 1450. After Perotto, Angelo Poliziano made a translation, published in 1497, that became extremely influential over the following centuries. Poliziano was a protégé of the Medici, and had access to the famous library of Lorenzo de Medici, to whom he dedicated his translation.

KEYWORDS: Poliziano. Epictetus. Renaissance. Stoicism. 


\section{Apresentação (A. Dinucci)}

Niccolò Perotto foi o primeiro a verter o Encheirídion para o latim em 1450. Após Perotto, Ângelo Poliziano realizou uma tradução que, publicada em $1497^{1}$, tornarse-ia extremamente influente ao longo dos séculos seguintes. Poliziano era um protegido dos Medici, tendo acesso à famosa biblioteca de Lorenzo de Medici, a quem dedicou sua tradução. Poliziano tinha em mãos dois manuscritos incorretos e com muitas lacunas: percebendo que havia ainda mais manuscritos assim, corrigiu o texto tomando por base o Comentário de Simplício ${ }^{2}$. Essa tradução de Poliziano pode ser encontrada na excelente edição italiana do Encheirídion de Epicteto realizada por Enrico Maltese ${ }^{3}$. Na carta-prefácio, Poliziano cita, tendo ele seguido o comentário de Simplício como Perotto, o proêmio do Comentário ao Encheirídion de Epicteto, afirmando que Arriano restitui a liberdade "àquele homem platônico, o homem verdadeiro", propriamente e verdadeiramente o homem é aquele cuja essência consiste inteiramente na alma racional" ". A versão latina de Poliziano do Encheirídion de Epicteto é dividida em sessenta e oito capítulos.

\footnotetext{
${ }^{1}$ POLIZIANO, A. Epicteti Stoici Enchiridion et Graeco interpretatum ab Angelo Poliziano. Veneza: J. Anthonium et Fratres de Sabio, 1528.

${ }^{2}$ Cf. POLIZIANO, Carta de Poliziano sobre o Encheirídion do estoico Epicteto traduzido por Poliziano do grego a Lourenzo de Medici. IN: MALTESE, E. Epitteto. Manuale. Milião: Garzanti, 1990, p. 61.

${ }^{3}$ Ibid., 1990.

${ }^{4}$ Ibid., p. 60.

${ }^{5}$ Ibid., p. 59.
} 


\section{Tradução (R. Quinalia)}

\section{Carta de Ângelo Poliziano a Lorenzo de Medici a respeito do Encheirídion do estoico Epicteto traduzido por Poliziano do grego}

Ó Lorenzo de Medici, escrevera Píndaro que o tessálio Ceneo, aquele que lutou contra os centauros, tornou-se àquela altura invulnerável e inatingível pelas armas. Mesmo quando os centauros todos juntos o prenderam em assalto, arremessando sobre ele um assustador amontoado de troncos, ele, fincando seus pés no solo - como Píndaro nos diz -, conseguira romper a terra ${ }^{6}$. O nosso Epicteto, por sua vez, recebera tais armas não de Vulcano, nem de Áquiles ou de Eneias, mas da própria natureza e do intelecto que o fizeram seguro e inviolável, não somente das agressões das lâminas e dos dardos, mas do medo, da dor e dos outros turbamentos d'alma. A guerra travada por este homem, não contra os centauros, como fez Ceneo, mas contra o acaso e a opinião, foi mais árdua: pois a ambas afugentou e pôs em fuga até bani-las totalmente de toda vida humana. Escravo, manco, mais pobre do que Íros ${ }^{7}$, não hesitara, todavia em um dístico muito conhecido entre os Gregos ${ }^{8}$, em proclamar-se caro aos deuses. Porque tinha lido em Platão, no diálogo intitulado Alcibíades I ou sobre a natureza humana, que propriamente e verdadeiramente o homem é aquele cuja essência consiste inteiramente na alma racional ${ }^{9}$. Por essa razão sustentava que qualquer coisa que fugisse do âmbito desse homem não poderia de modo nenhum atingi-lo. E não teria declarado somente com palavras e nos livros, mas também com sua própria vida: justamente removera de si mesmo o cuidado das coisas externas. Sua casa, em Roma, não tinha nem mesmo uma porta, já que nesta não havia absolutamente nada, a não ser um mísero apanhado de feno, sua cama ${ }^{10}$.

Sobre sua vida e sobre sua índole o celebre Arriano compôs um amplo volume ${ }^{11}$, que, no entanto perdeu-se nos séculos passados, e da sua obra, teria colhido, por assim dizer, o nectar ${ }^{12}$, aquilo que restituiu a liberdade àquele platônico, àquele verdadeiro

\footnotetext{
${ }^{6} \mathrm{O}$ exórdio da carta é paráfrase de Plut. De absurd. Stoic. opin.1, 1057d. Quanto ao fragmento de Píndaro proposto pela passagem de Plutarco, cf. P. Oxy. 26, 2447 (Thren. VI, frag. 128f Snell-Maehler).

${ }^{7}$ Mendigo que, na Odisseia, faz-se pretendente de Penélope.

${ }^{8}$ Epigrama anônimo presente na Antologia Palatina. VII 676.

${ }^{9}$ Cf. Platão, Alcibiades I, 129b e Simplício, Comentário ao Encheirídion de Epicteto, Proêmio.

${ }^{10}$ Cf. Simplício, Comentário ao Encheirídion de Epicteto, Proêmio, 37-40D).

${ }^{11}$ Cf. Simplício, Comentário ao Encheirídion de Epicteto, Proêmio, 5-8D.

${ }^{12}$ Literalmente: "teria colhido a flor", i.e. o que há de mais nobre na obra.
} 
homem, e o colocara em um livro. E uma vez que é um bem ter esse livro sempre às mãos, o intitulara Encheirídion, o nome de um pequeno punhal militar. Sua linguagem é extremamente eficaz e enérgica, incrivelmente capaz de atingir o leitor como um ferrão que nos penetra, porque naquelas palavras cada um de nós reconhece as próprias paixões. É de se admirar, por toda a obra, a sua organização: mesmo se o trabalho é dividido em mais de um capítulo, todas suas linhas, por assim dizer, convergem como para um só centro, despertando a alma racional para que se preocupe com sua própria dignidade e para o uso das suas próprias ações de acordo com a natureza ${ }^{13}$. O estilo, aliás, como exige a situação, é conciso, nítido e privo de qualquer adorno, muito similar aos preceitos dos Pitagóricos, que estes denominavam diathekai ${ }^{14}$.

No meu empenho em traduzi-lo para o latim, para que de alguma maneira eu possa te agradecer por nos regalar essa sublime possibilidade de enriquecer nossa literatura, trabalhei com dois exemplares repletos de erros, muitas vezes com lacunas gravíssimas. Por isso, informado que as outras cópias, onde quer que elas estejam não são diferentes destas, tomei a liberdade, lá onde faltava um capitulo ou quando o mesmo se encontrava mutilado, de preenchê-lo com base nas palavras de Simplício, autor de um comentário da obra, atendo-me a ele do modo mais fiel possível. E se não agarrei mais fielmente as suas palavras (o que de fato não era possível), acredito de ter conseguido transformá-las em um latim límpido e claro. Esperando que este fato não disturbe ninguém, como Aristarco ${ }^{15}$ fez com os versos de Homero, assim atravessamos com um obelos, isto é, com um espeto, cada um dos capítulos que resultaram interpretados com nossas palavras ${ }^{16}$.

Portanto, Lorenzo, encontra, em meio as suas ocupações, um retalho de tempo e dedica-te à leitura desse pequeno livrinho. $\mathrm{O}$ ensinamento que dele emerge, se avaliado de maneira reta, é de um gênero que fala justamente a todos aqueles que a sorte elevou. Em todo caso, aquilo que por todo o opúsculo se explica mediante muitas palavras, Epicteto exprime em dois verbos: Suporta e Abstém-te ${ }^{17}$.

Este homem tinha uma pátria, era uma cidade da Frígia, Hierápolis. Em Roma vivera até os tempos de Marco Antônio ${ }^{18}$, foi escravo de um empregado de Nero, certo

\footnotetext{
${ }^{13}$ Cf. Simplício, Comentário ao Encheirídion de Epicteto, Proêmio, 17-24D.

${ }^{14}$ Cf. Simplício, Comentário ao Encheirídion de Epicteto, Proêmio 15-17 D. Simplício, entretanto, fala de hypothékai, não de diathékai.

${ }^{15}$ Famoso filólogo que viveu na primeira metade do séc. II. a.C.

${ }^{16}$ Os obeloi de Poliziano não figuram nem no Riccardiano, nem, obviamente, nas edições impressas.

${ }^{17}$ Cf. Aulo Gélio XVII 19, 6 (= Epict. Fr. X p. 463, 33-34 Sch); Marco Aurélio V 33, 6, etc.

${ }^{18}$ Cf. Suda E 2424 (II, p. 365, 24-27).
} 
Epafrodito. No entanto, sob o império de Domiciano, ameaçado pelo tirano, exilou-se em Hierápolis ${ }^{19}$, convicto da verdade do que afirma um poeta trágico: que a verdadeira pátria é o lugar onde se pode viver retamente ${ }^{20}$. Todos se admiraram pelo modo que conduzia sua vida, tanto que o sírio Luciano relata que o lampião de terracota de Epicteto um dia a ele pertencera, fora vendido por três mil dracmas ${ }^{21}$.

Agora, Lourenzo, envio-te não o lampião de Epicteto, mas uma imagem muito mais luminosa da sua alma. Nestes dias, examinando atentamente, de fato, todo o tesouro desta sua belíssima biblioteca onde orgulhosamente tive a honra de poder trabalhar, te oferto esse opúsculo como te ofereceria uma flor de um jardim. Este, todavia, é o livro, se não me engano, que mais do que qualquer outro se harmoniza com tua natureza, sempre pronta para as coisas grandes e árduas, e nestes tempos tão duros, onde a sorte te pôs à prova. Adeus.

\section{REFERÊNCIAS BIBLIOGRÁFICAS}

AÉLIO ESPARTANO. Vida de Adriano. IN: Historia Augusta, vol. 1. Trad. D. Magie. Harvard: Loeb Classical Library, 1921.

AGOSTINHO. The City of God against the pagans. Harvard: Cambridge University Press, 1998.

AGOSTINHO. Nicene and post-nicene fathers. Anti-Pelagian Writings. Philip Schaff (ed.).New York: Christian Literature Publishing Co., 1886. Disponível para download em http://www.ccel.org/ccel/schaff/npnf105.html

ANTONIO DE SOUZA. Manual de Epicteto Filósofo. Lisboa: Regia Officina Tipografica, 1785 . Disponível para download em http://books.google.com.br/books?id=umUBAAAAMAAJ\&printsec=frontcover\&dq $=\mathrm{e}$ pictetus\&hl $=\mathrm{pt}-$

$\underline{\text { BR\&ei }=\text { LcLCTZmDPMj50gGDosjtAw\&sa }=X \& \text { oi }=\text { book result\&ct }=\text { result\&resnum }=8}$ \&ved $=0$ CEsQ6AEwBw\#v=onepage \&q \&f $=$ false.

ASHLEY, A. The Life, unpublished letters and philosophical regimen of Anthony, Earl of Shaftesbury. Londres: Swan Sonnenschein \& Co, 1900.

AULO GÉLIO. Noctium Atticarum. Harvard: Loeb, 2002.

\footnotetext{
${ }^{19}$ Cf. Simplício, Comentário ao Encheirídion de Epicteto, Proêmio, 36-37D; Aulo Gélio. XV 11, 4-5.

${ }^{20}$ Cf. Cícero, Tusculanae, 37, 108.

${ }^{21}$ Luc. $A d v$. ind. 13.
} 
BLAISE PASCAL. Colóquio com o Senhor de Saci Sobre Epicteto e Montaigne. Tradução de Jaimir Conte. Princípios, Natal, vol. 12, nos 17-18, jan./dez. 2005, p.185188.

BOTER, G. The Encheiridion of Epictetus and its Three Christian Adaptations: Transmission \& Critical Editions. Leiden: Brill, 1999.

BOTER, G. Epictetus Encheiridion. Berlim: De Gruyter, 2007.

BROOKE, C. Epictetus in Early Modern Europe: 1453-1758. Professor A. A. Long's Epictetus seminar, 14 de Abril de 1999. Berkeley: 1999, p. 1-21.

DINUCCI A. O Manual de Epicteto. Aforismos da Sabedoria Estoica. São Cristóvão, EdiUFS, 2007.

DINUCCI A. Introdução ao Manual de Epicteto. São Cristóvão, EdiUFS, 2007. Disponível em: http://seer.ufs.br/index.php/prometeus/issue/view/111

DINUCCI A; JULIEN A. Epicteto: testemunhos e fragmentos. São Cristóvão, EdiUFS, 2008. Disponível em: http://seer.ufs.br/index.php/prometeus/issue/view/107

DINUCCI A; JULIEN A. O Encheirídion de Epicteto: Edição bilíngue. São Cristóvão, EdiUFS, 2012. Disponível em: http://seer.ufs.br/index.php/prometeus/issue/view/112 EPICTETO. The Discourses of Epictetus as reported by Arrian; Fragments; Encheiridion. Trad. Oldfather. Harvard: Loeb, 2000.

EPICTETO. O manual de Epicteto. Trad. Hans Koranyi. São Paulo: Agência Editora Iris, 1959.

EPICTETO. O Manual de Epicteto, filósofo. Trad. Frei Antônio de Sousa. São Paulo, Ed. Cultura, 1941.

EPICTETO. Manual; Fragmentos. Trad. Paloma Ortiz García. Madrid: Editorial Gredos, 1995.

ESTOBEU. Florilegium, vol I e II. Augustus Meineke (ed.). Lipsiae: Taubner, 1855.

GEANAKOPLOS, Deno John. Greek Scholars in Venice: Studies in the Dissemination of Greek Learning from Byzantium to the West. Cambridge: Harvard, 1962.

GÉLIO, A. Noctium Atticarum. Harvard, Loeb, 2002.

HADOT, I. Simplicius. Commentaire sur le Manuel d'Épictète, Introduction et édition critique du texte grec. Leiden: Brill, 1996.

LABOWSKY, C. Bessarion's Library and the Biblioteca Marciana. Rome: Edizioni di storia e letteratura, 1979.

LEOPARDI, G. Epictteto: Manuale. Milão: Rizzoli, 1996. 
LEOPARDI. Opere di Giacomo Leopardi. Edizione acresciuta, ordinata e corretta.

Antonio Ranieri (Ed.). Firenze: Felice Le Monnier, 1845.

LUCIANO. Volume III. Trad. Harmon A. M. Harvard, Loeb, 1921.

MALTESE, E. Epitteto. Manuale. Milião: Garzanti, 1990.

MARCO AURÉLIO ANTONINO. Marcus Aurelius. Trad. C. R. Haines. Harvard: Loeb, 1916.

NICOLO PEROTTO. Epicteti enchiridium a Nicolao perotto e graeco in latinum translatum. Veneza, 1453.

PENDLETON OLIVER, R. Niccolo Perotti's Version of The Enchiridion of Epictetus.

Urbana: Illinois, 1954.

ORÍGENES. Contra Celsum. IN: PATROLOGIA GRAECAE 11-17, 3.368.

PEROTTO, N. Epicteti enchiridium a Nicolao perotto e graeco in latinum translatum. Veneza, 1453.

PLATÃO. First Alcibiades. Trad. W. R. M. Lamb. Harvard: Loeb Classical Library,1927.

POLIZIANO, A. Epicteti Stoici Enchiridion et Graeco interpretatum ab Angelo Poliziano. Veneza: J. Anthonium et Fratres de Sabio, 1528.

SCHENKL H. Die Epiktetishen Fragmente. Sitzungsberichte der philos. - hist. Calsse der K. Akad. der Wiss. Viena, 115 (1888), P. 443-546.

SCHENKL H. Epicteti Dissertationes ab Arriano digestae. Epictetus. Leipzig: B. G. Teubner, 1916

SCHWEIGHAUSER. Epicteteae Philosophiae Monumenta. 3 vol. Leipzig: Weidmann, 1798.

SIMPLÍCIO. Commentaire sur le Manuel d'Épictète, Introduction et édition critique du texte grec. Leiden: Brill, 1996.

SIMPLÍCIO. On Epictetus Handbook. 1-26. Trad. C. Brittain; T. Brennan. New York: Cornell, 2002.

SMITH, W. SIR. Dictionary of Greek and Roman antiquities. Ed. William Smith. Illustrated by numerous engravings on wood. Boston: C. Little, and J. Brown, 1870.

SPALATIN C. A. Matteo Ricci's use of Epictetus. Korea: Waegwan, 1975.

SPANNEUT. Épictète chez les moines. MSR, 29, 1972.

STADTER, P. Arrian of Nicomedia. Virginia: UNC Press, 1980.

SUIDAS. Suda. Disponível em: http://www.stoa.org/sol/ 
TEMÍSTIO. Orations 6-8. Letters to Themistius, To the Senate and People of Athens, To a Priest. The Caesars. Misopogon. Trad. Wilmer, C. Harvard: Loeb, 1913.

TRINCAVELLI. Arriani Epictetus Graeche. Veneza: 1535.

UPTON J. Epicteti quae supersunt dissertationes ab Arriano collectae nec non Enchiridion et fragmenta Graece et Latine ... cum integris Jacobi Schegkii et Hieronymi Wolfii selectisque aliorum doctorum annotationibus, 2 vol. Londres: Thomae Woodward, 1741.

WOLF. H. Epicteti Enchiridion: una cum Cebetis Thebani Tabula Groec. \& Lat. Quibus... accesserunt e graeco translata Simplicii in eundem Epicteti libellum doctissima scholia, Arriani commentarium de Epicteti disputationibus libri iiii, item alia ejusdem argumenti in studiosorum gratiam. Basiléia: 1563. 